\title{
Preoperative prediction of long-term survival after coronary artery bypass grafting in patients with low left ventricular ejection fraction
}

\author{
Joseph J. DeRose, Jr, MD ${ }^{\mathrm{a}}$ \\ Ioannis K. Toumpoulis, MD \\ Sandhya K. Balaram, MD, PhD \\ John P. Ioannidis, $M D^{\mathrm{b}, \mathrm{c}}$ \\ Scott Belsley, MD ${ }^{\text {a }}$ \\ Robert C. Ashton, Jr, MD \\ Daniel G. Swistel, MD \\ Constantine E. Anagnostopoulos, MD ${ }^{\mathrm{a}, \mathrm{d}}$
}

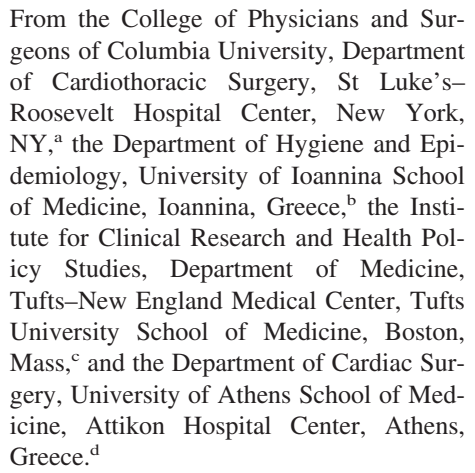

Received for publication Feb 21, 2004; revisions received May 18, 2004; accepted for publication May 24, 2004

Address for reprints: Joseph J. DeRose, Jr, MD, Department of Cardiothoracic Surgery, St Luke's-Roosevelt Hospital Center, 1111 Amsterdam Ave, MU217, New York, NY 10025 (E-mail: jjd11@columbia.edu).

J Thorac Cardiovasc Surg 2005;129:314-21

$0022-5223 / \$ 30.00$

Copyright $\odot 2005$ by The American Association for Thoracic Surgery

doi:10.1016/j.jtcvs.2004.05.022
Objective: We aimed to develop multivariable models of preoperative risk factors that predict long-term survival after coronary artery bypass grafting in patients with ejection fraction $25 \%$ or less.

Methods: We retrospectively evaluated 544 consecutive patients with ejection fraction $25 \%$ or less who underwent coronary artery bypass grafting from 1992 to 2002 at a single institution. Long-term survival data (mean follow-up 4.1 years) were obtained from the National Death Index. Multivariable Cox regression analysis was performed to construct a predictive score for long-term mortality. A splitsample approach was also used building a model on a training group $(\mathrm{n}=360)$; this model was then tested on a separate validation group $(n=184)$.

Results: From the entire database, the predictive score was calculated according to the following equation: 0.430 (if past congestive heart failure) +0.049 (age in years) +0.507 (if peripheral vascular disease) +0.580 (if emergency operation) +0.366 (if chronic obstructive pulmonary disease). The 5-year survivals of the predictive score quartiles were $82.3 \%, 78.2 \%, 65.5 \%$, and $45.5 \%(P<.0001)$. The model based on the training group had four independent predictors for long-term mortality (the same as the listed equation except for past congestive heart failure). The 5-year survival rates of the quartiles were $90.1 \%, 75.4 \%, 64.3 \%$, and $49.2 \%$ in the training group $(P<.0001)$ and $77.4 \%, 71.2 \%, 65.8 \%$, and $45.5 \%$ in the validation group $(P=$ $.0001)$.

Conclusion: Coronary artery bypass grafting in patients with severe ischemic cardiomyopathy achieves satisfactory midterm and long-term survival in selected patients. This new score, which is based on long-term data from a large number of patients, may aid clinicians in selecting therapeutic interventions for patients with ischemic cardiomyopathy.

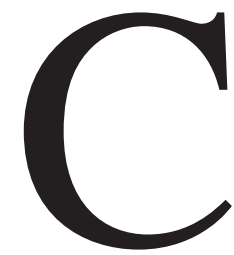
ongestive heart failure (CHF) affects more than 5 million Americans and contributes to a growing number of hospital admissions. ${ }^{1}$ The most common cause of CHF worldwide is coronary artery disease. ${ }^{2}$ Left ventricular dysfunction of ischemic etiology is associated with approximate 5-year survivals of $40 \%$ with medical treatment and $60 \%$ with coronary artery bypass grafting $(\mathrm{CABG}){ }^{3}$ Multiple therapeutic options for patients with low left ventricular ejection fraction 
(EF) are available, including medical therapy, CABG, biventricular pacing, ventricular-assist devices and orthotopic heart transplantation. ${ }^{3-7}$ Selecting between CABG and other interventions is difficult, and the choice would be facilitated if prognostic factors for long-term outcomes were known. It has been shown in multiple studies that CABG results in considerable improvement in long-term survival, as well as quantitative improvements in EF and symptomatic New York Heart Association (NYHA) class. ${ }^{8-14}$ However, there is no full consensus on exactly which patients have the greatest potential for long-term survival.

Multiple preoperative risk factors have been associated in previous studies with decreased survival benefit. These include age at the time of surgery, female sex, emergency status, end-systolic volume index, number of previous myocardial infarctions, the quality of coronary arteries, complete revascularization, myocardial viability, left ventricular end diastolic pressure, and NYHA functional class IV status. ${ }^{8,11,12,14-19}$ These various risk factors may increase mortality to a point that outweighs any potential long-term benefits of revascularization. In this study, we used longterm follow-up data of 544 consecutive patients with low $\mathrm{EF}(\leq 25 \%)$ to create a preoperative score that can be used in predicting long-term $\mathrm{CABG}$ risk for death and assist in determining therapy for patients with a markedly low EF and coronary artery disease.

\section{Materials and Methods}

\section{Patient Population and Data}

Our study consisted of 544 consecutive patients with low EF $(\leq 25 \%)$, who underwent isolated CABG between January 1992 and March 2002 at the St. Luke's-Roosevelt Hospital Center affiliated with Columbia University College of Physicians and Surgeons in New York. Patients who underwent concomitant valve surgery or aneurysmectomy were excluded from the study. Indications for CABG were based on standard clinical and angiographic criteria. Complete revascularization was the policy of our institution, and reliance on echocardiography, particularly transesophageal echocardiography, in addition to anatomy determined the number of anastomoses. Moving and thick segments indicating myocardial viability were all revascularized.

Data were prospectively collected during admission as part of routine clinical practice and entered into the New York State adult cardiac surgery report for the variables shown in Tables 1 and 2. CHF was diagnosed by paroxysmal nocturnal dyspnea or dyspnea on exertion from heart failure or chest radiograph showing pulmonary congestion. CHF was characterized as current when diagnosed within 2 weeks before the procedure or past when diagnosed between 2 weeks to 6 months before the procedure. Peripheral vascular disease (PVD) was diagnosed by one of the following criteria: (1) a history of stroke with or without residual deficit; (2) angiographic or ultrasonographic demonstration of at least 50\% narrowing in a major cerebral or carotid artery (common or internal) and history of nonembolic stroke or previous surgery for such disease (a history of bruits or transient ischemic attacks is not sufficient evidence for carotid or cerebrovascular disease); (3)
TABLE 1. Patient and disease characteristics in patients with low EF undergoing CABG $(\leq 25 \%, n=544)$

\begin{tabular}{|c|c|}
\hline Age $(y$, mean $\pm S D)$ & $65.2 \pm 10.1$ \\
\hline Female (No.) & $143(26.3 \%)$ \\
\hline \multicolumn{2}{|l|}{ Race (No.) } \\
\hline White & $308(56.6 \%)$ \\
\hline Black & $123(22.6 \%)$ \\
\hline Other & $113(20.8 \%)$ \\
\hline \multicolumn{2}{|l|}{ Vessels involved (No.) } \\
\hline One-vessel disease & $10(1.8 \%)$ \\
\hline Two-vessel disease & $89(16.4 \%)$ \\
\hline Three-vessel disease & $445(81.8 \%)$ \\
\hline Unstable angina (No.) & $446(82.0 \%)$ \\
\hline $\begin{array}{l}\text { Canadian Cardiovascular Society angina } \\
\quad \text { class (mean } \pm \text { SD) }\end{array}$ & $3.79 \pm 0.50$ \\
\hline Previous myocardial infarction (No.) & $360(66.2 \%)$ \\
\hline Transmural myocardial infarction (No.) & $302(55.5 \%)$ \\
\hline More previous myocardial infarction (No.) & $200(36.8 \%)$ \\
\hline \multicolumn{2}{|l|}{ Urgency of operation (No.) } \\
\hline Emergency & $91(16.7 \%)$ \\
\hline Urgent & $345(63.4 \%)$ \\
\hline Elective & $108(19.9 \%)$ \\
\hline Previous cardiac operation (No.) & $40(7.4 \%)$ \\
\hline $\begin{array}{l}\text { Previous percutaneous coronary } \\
\text { intervention (No.) }\end{array}$ & $51(9.4 \%)$ \\
\hline Ejection fraction $(\%$, mean \pm SD) & $18.6 \pm 6.4$ \\
\hline Hemodynamic instability (No.) & $37(6.8 \%)$ \\
\hline Shock (No.) & $9(1.7 \%)$ \\
\hline Nitroglycerin 24 h before operation (No.) & $144(26.5 \%)$ \\
\hline Thrombolysis (No.) & $40(7.4 \%)$ \\
\hline Myocardial rupture (No.) & $1(0.2 \%)$ \\
\hline Current CHF (No.) & $250(46.0 \%)$ \\
\hline Past CHF (No.) & $149(27.4 \%)$ \\
\hline PVD (No.) & $147(27.0 \%)$ \\
\hline Body mass index $\left(\mathrm{kg} / \mathrm{m}^{2}\right.$, mean $\left.\pm \mathrm{SD}\right)$ & $21.3 \pm 4.5$ \\
\hline Hypertension (No.) & $383(70.4 \%)$ \\
\hline Left ventricular hypertrophy (No.) & $168(30.9 \%)$ \\
\hline COPD (No.) & $122(22.4 \%)$ \\
\hline Preoperative intra-aortic balloon pump (No.) & $104(19.1 \%)$ \\
\hline Diabetes mellitus (No.) & $248(45.6 \%)$ \\
\hline Calcified aorta (No.) & $77(14.2 \%)$ \\
\hline Hepatic failure (No.) & $2(0.4 \%)$ \\
\hline Renal failure (No.) & $22(4.0 \%)$ \\
\hline Dialysis (No.) & $16(2.9 \%)$ \\
\hline Immune deficiency (No.) & $4(0.7 \%)$ \\
\hline Smoking past 2 wk (No.) & $109(20.0 \%)$ \\
\hline Smoking past 1 y (No.) & $87(16.0 \%)$ \\
\hline
\end{tabular}

angiographic demonstration of at least $50 \%$ narrowing in a major aortoiliac vessel and previous surgery for such disease, absent femoral pulses, or inability to insert a catheter or intra-aortic balloon pump because of iliac aneurysm or obstruction of the aortoiliac arteries (tortuosity of the vessel alone does not constitute aortoiliac disease as well as abdominal aortic aneurysm, history of aortobifemoral bypass, and absence of a femoral pulse on either right or left); and (4) angiographic demonstration of at least $50 \%$ 
TABLE 2. Intraoperative characteristics, early mortality, length of stay and major complication after CABG in patients with low EF ( $\leq 25 \%, n=544)$

\begin{tabular}{lc}
\hline Intraoperative characteristics & \\
Two or more arterial grafts (No.) & $259(47.6 \%)$ \\
Number of distal anastomoses (mean \pm SD) & $3.4 \pm 0.9$ \\
OPCAB (No.) & $82(15.1 \%)$ \\
Microscope use (No.) & $234(43.0 \%)$ \\
Early mortality and length of stay & \\
EuroSCORE standard (mean \pm SD) & $8.25 \pm 2.82$ \\
30-d mortality (No.) & $30(5.5 \%)$ \\
In-hospital death (No.) & $33(6.1 \%)$ \\
Stay (d, mean \pm SD) & $13 \pm 11.3$ \\
Major complications & \\
Intraoperative stroke (No.) & $25(4.6 \%)$ \\
Over 24 h stroke (No.) & $4(0.7 \%)$ \\
Postoperative myocardial infarction (No.) & $5(0.9 \%)$ \\
Deep sternal wound infection (No.) & $9(1.7 \%)$ \\
Bleeding/reoperation (No.) & $14(2.6 \%)$ \\
Sepsis/endocarditis (No.) & $7(1.3 \%)$ \\
Gastrointestinal bleeding, perforation, & $12(2.2 \%)$ \\
$\quad$ or infarction (No.) & \\
Renal failure/dialysis (No.) & $11(2.0 \%)$ \\
Respiratory failure (No.) & $42(7.7 \%)$
\end{tabular}

narrowing in a major femoral or popliteal vessel and previous surgery for such disease, absent pedal pulses, or inability to insert a catheter or intra-aortic balloon pump because of obstruction in the femoral arteries (both dorsalis pedis and posterior tibial need to be absent in one foot; a negative popliteal pulse alone does not constitute femoral or popliteal disease as well as medications for PVD without indication of femoral or popliteal disease). Chronic obstructive pulmonary disease (COPD) was diagnosed by one of the following criteria: (1) chronic bronchodilator therapy to avoid disability from obstructive airway disease longer than 3 months, (2) a forced expiratory volume in 1 second less than $75 \%$ of the predicted value or less than $1.25 \mathrm{~L}$, and (3) a room air $\mathrm{PaO}_{2}$ less than $60 \mathrm{~mm} \mathrm{Hg}$ or $\mathrm{PaCO}_{2}$ greater than $50 \mathrm{~mm} \mathrm{Hg}$. Preoperative risk stratification was performed according to the EuroSCORE model. ${ }^{20}$

\section{Data Analysis}

Long-term patient mortality data were obtained from the United States Social Security Death Index database (http://ssdi.genealogy.rootsweb.com). The sensitivity of the National Death Index to identify deaths is between $92 \%$ and $99 \%$, depending on which identifiers are available. ${ }^{21}$ Social Security number alone has the best accuracy of any combination of other identifiers (first initial, last name day of birth, month of birth, year of birth, etc), with a sensitivity of $97 \%$ and a specificity of $99 \%{ }^{21}$ In this study we used only Social Security numbers, which were available for most patients (98.7\%); this allowed us to avoid the use of patients' names. Moreover, patients without a Social Security number $(\mathrm{n}=$ 7) were censored at the time of discharge from the hospital. The index was queried in September 2002, and patients not found in the index were assumed to be alive at that date.
TABLE 3. Potential predictors for long-term mortality in patients with low $\mathrm{EF}(\leq 25 \%)$ undergoing CABG (univariate Cox regression analysis)

\begin{tabular}{lccr}
\hline \multicolumn{1}{c}{ Variable } & HR & $\begin{array}{c}\text { 95\% Confidence } \\
\text { interval }\end{array}$ & $\boldsymbol{P}$ value \\
\hline $\begin{array}{l}\text { Age (continuous } \\
\text { variable) }\end{array}$ & 1.053 & $1.037-1.070$ & $<.001$ \\
$\begin{array}{l}\text { Body mass index } \\
\quad \text { (continuous variable) }\end{array}$ & 1.047 & $1.016-1.079$ & .003 \\
$\begin{array}{l}\text { Emergency operation } \\
\text { Urgent operation }\end{array}$ & 1.83 & $1.30-2.58$ & .001 \\
PVD & 0.71 & $0.55-0.97$ & .003 \\
COPD & 1.93 & $1.44-2.58$ & $<.001$ \\
Current CHF & 1.53 & $1.13-2.09$ & $<.001$ \\
Past CHF & 1.40 & $1.06-1.86$ & .019 \\
Calcified aorta & 1.50 & $1.11-2.04$ & .009 \\
Immune deficiency & 1.91 & $1.36-2.69$ & $<.001$ \\
OPCAB surgery & 5.70 & $1.39-23.31$ & .016 \\
& 1.77 & $1.17-2.67$ & .007 \\
\hline
\end{tabular}

\section{Statistical Methods}

Numerica variables are presented as mean $\pm \mathrm{SD}$, whereas discrete variables were summarized by percentages. Multivariable Cox proportional hazard regression models ${ }^{22}$ were used to reveal the statistically significant risk factors that were associated with longterm mortality. Hazard ratios (HRs) and 95\% confidence intervals were calculated. The model selection was done with backward stepwise method starting from all variables with $P<.05$ in univariate analyses. Interaction terms were considered but were not important. Continuous variables were checked for conformity with linear gradient. This multivariable model was then used to calculate a predictive score for long-term mortality after CABG.

We also used a split-sample approach. The total number of patients was divided randomly into two groups (training and validation sets). We built a multivariable model from the data of the 360 patients in the training set, and we tested the discriminating performance of the derived model on the remaining 184 patients of the validation set. The coefficients of the model derived in the full data set may be inflated because of overfitting; that is, the relative differences in prognosis between the risk quartiles may be smaller than suggested by the full data set model. This is not a problem in the split-sample approach. A measure of the potential shrinkage that needs to be applied to the coefficients of the full data set model may be obtained from the shrinkage slope $b$ of a Cox regression that is modeling (in the validation data set) the relative hazard of death as a function of the score derived in the training data set. ${ }^{23}$ We estimated the shrinkage $b$ in our data.

For all models tested, we generated Kaplan-Meier curves $^{24}$ according to score quartiles, and the four curves were compared with the log-rank test, with adjustment for trend as appropriate. We also estimated for each model and data set the extreme quartile odds ratio $(\mathrm{EQuOR})^{25}$; that is, the odds of death in the high-risk quartile divided by the odds of death in the low-risk quartile. The larger the EQuOR value, the better the discrimination of a model between high- and low-risk patients. All analyses were performed with SPSS version 11.0 software (SPSS, Inc, Chicago, Ill), and all $P$ values are 2-tailed. 

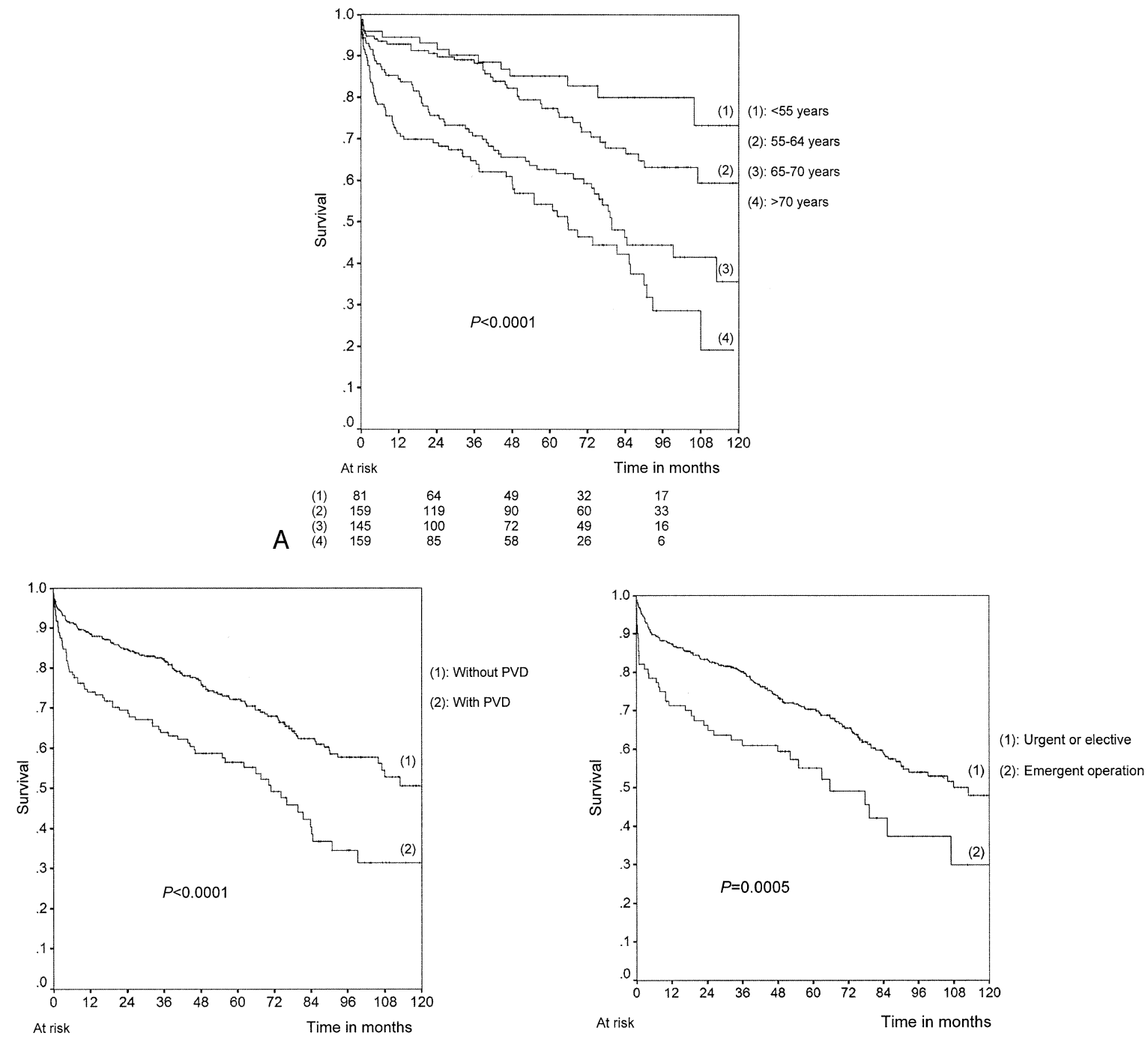

$\begin{array}{ccccccc}\text { B } & \text { (1) } & 397 & 280 & 203 & 136 & 58 \\ (2) & 147 & 88 & 66 & 31 & 14\end{array}$

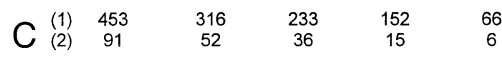
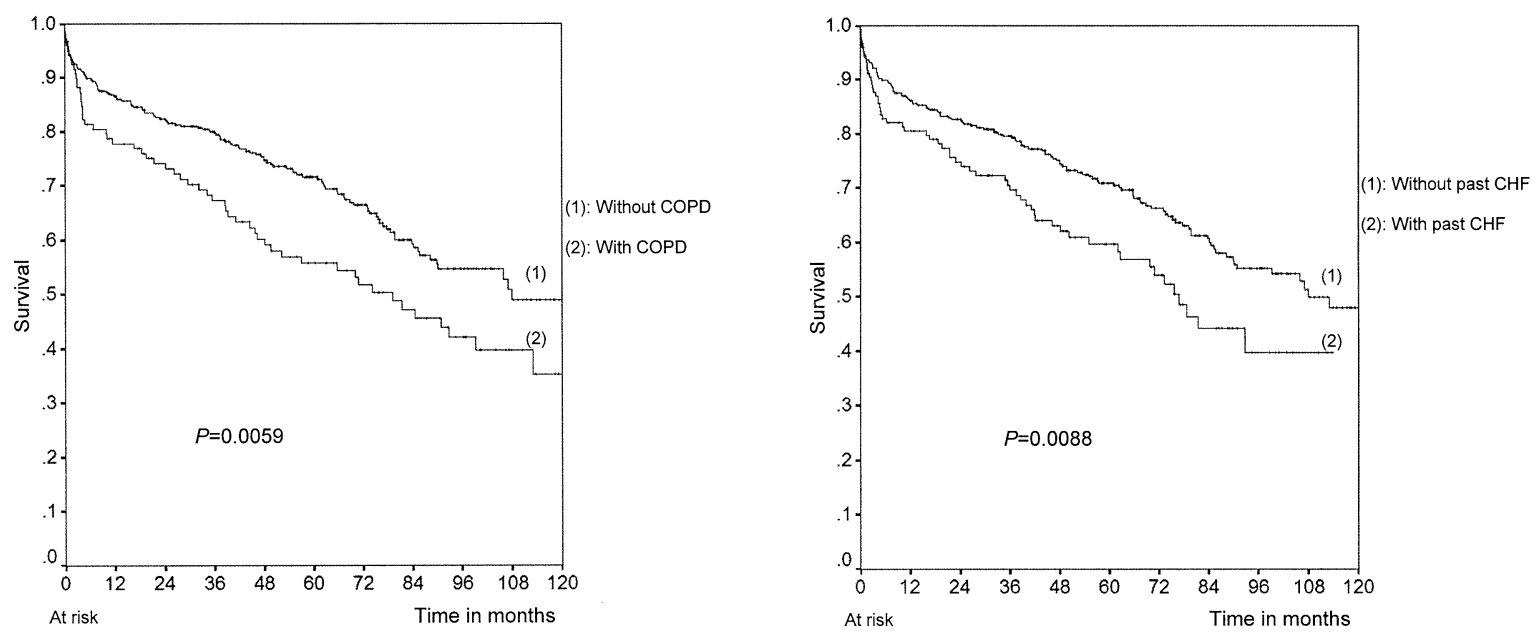

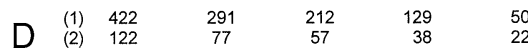

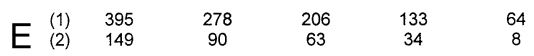

Figure 1. Kaplan-Meier curves of patients with low EF $(\leq 25 \%)$ according to each independent predictor of long-term mortality. A, Age. B, PVD. C, Emergency operation. D, COPD. E, Past CHF. 


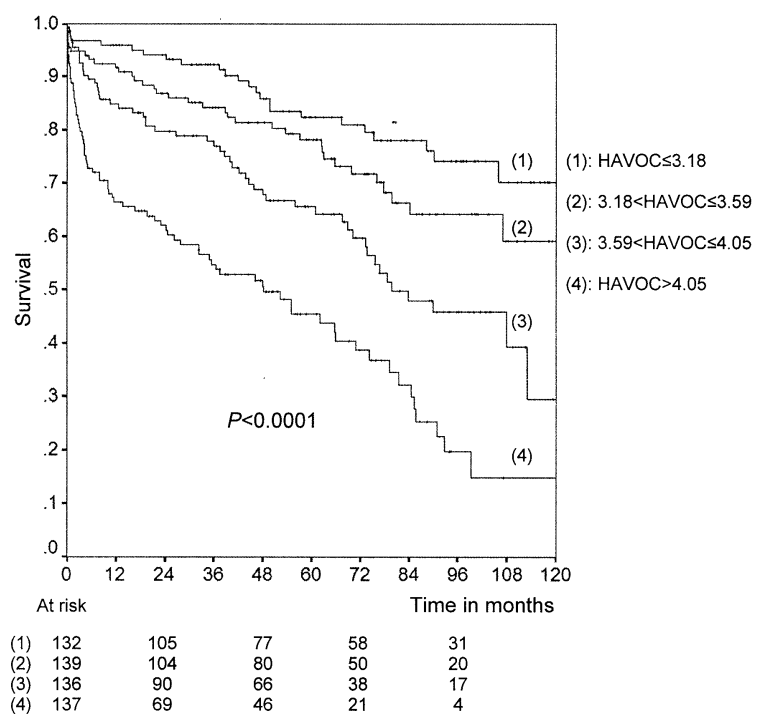

Figure 2. Kaplan-Meier curves of quartiles according to constructed HAVOC score of all patients with low EF $(\leq 25 \%)$ undergoing CABG ( $\mathrm{n}=544)$.

\section{Results}

\section{Clinical Characteristics, Early Outcome, and Long- Term Survival}

Patient and disease characteristics are summarized in Table 1. The mean standard EuroSCORE of the 544 patients was $8.25 \pm 2.82$. During 2214 patient-years of follow-up (mean follow-up $4.1 \pm 3.1$ years), 192 deaths $(35.3 \%)$ were recorded. Table 2 summarizes the procedural data, early mortality, and length of stay, as well as major complications after CABG, in the study cohort. Thirty-day mortality in this series of patients with low EF was 5.5\%, and 1-, 5-, and 10 -year survivals were $85 \% \pm 2 \%, 68 \% \pm 2 \%$ and $45 \% \pm$ $4 \%$, respectively. Most patients (81.8\%) had three-vessel disease, and the mean number of anastomoses per patient was 3.4, indicating a high proportion of complete revascularization. Almost half the patients received two or more arterial grafts including bilateral internal thoracic arteries, and almost 1 in 6 patients underwent off-pump CABG $(\mathrm{OPCAB})$. The 5-year survival in this subgroup of patients was $45 \% \pm 4 \%$, versus $70 \% \pm 2 \%$ in the on-pump subgroup $(P=0.006)$; however, patients undergoing OPCAB had higher EuroSCORE (9.3 vs 8.0, $P<.001)$.

\section{Building a Predictive Score for the Entire Database}

The results of univariate Cox regression analysis are shown in Table 3. In multivariable Cox regression analysis the retained independent predictors for long-term mortality in the overall data set, included past $\mathrm{CHF}$ (HR 1.54, $P=.006$ ), $a$ ge (HR 1.050 per year, $P<.001$ ), PVD (HR 1.66, $P=$ .001 ), emergency operation (HR 1.79, $P=.001$ ), and COPD (HR 1.44, $P=.021$ ). We called the score derived from these factors the HAVOC score. Kaplan-Meier curves of all 544 patients with low EF stratified according to each of these independent predictors of long-term mortality are shown in Figure 1.

The predictive score that was based on these five factors was calculated according to the following: equation HAVOC $=0.430($ if past CHF $)+0.049($ age in years $)+$ 0.507 (if peripheral vascular disease) +0.580 (if emergency operation) + 0.366(if COPD). We divided all patients into quartiles according to HAVOC score, and we estimated the survival for each quartile as shown in Figure 2. The KaplanMeier curves of the quartiles diverged widely (5-year survival rates: $82.3 \%, 78.2 \%, 65.5 \%$, and $45.5 \%$ ), and this was highly statistically significant (log-rank test adjusted for trend $P<.0001$ ). The EQuOR was 6.0. There were also differences among the quartiles of the HAVOC score in terms of 30-day mortality: $3.0 \%, 2.9 \%, 5.1 \%$, and $10.9 \%$ from low- to high-risk group $(P=.011)$.

\section{Split-Sample Model}

Multivariable Cox regression analysis for the training set retained as independent predictors for long-term mortality in this group of patients the following variables: age (HR 1.052 per year, $P<.001$ ), PVD (HR 1.72, $P=.004$ ), emergency operation (HR 1.90, $P=.003$ ), and COPD (HR $1.50, P=.043)$. We calculated the new score by the following new equation $S=0.051$ (age in years) +0.543 (if PVD) + 0.641(if emergency operation) +0.405 (if COPD). We obtained a shrinkage coefficient of 0.78. The KaplanMeier curves of the quartiles diverged widely in both groups, as shown in Figure 3, and this was statistically significant not only in the training set (log-rank test adjusted for trend $P<.0001)$ but also in the validation group $(P=$ $.0001)$. The survival rates in the quartiles in the training set were $90.1 \%, 75.4 \%, 64.3 \%$, and $49.2 \%$, and the EQuOR was 8.4. The survival rates in the validation set were $77.4 \%$, $71.2 \%, 65.8 \%$, and $45.5 \%$, and the EQuOR in the validation set was 3.7.

\section{Discussion}

This study is one of the largest to examine long-term survival data and risk factors in patients undergoing CABG for ischemic cardiomyopathy. On the basis of these data, we have proposed a predictive score for long-term survival after CABG in patients with low EF. We determined that independent preoperative predictors for long-term mortality included past $\mathrm{CHF}$, age at time of surgery, $\mathrm{P} V \mathrm{D}$, emergency operation, and COPD, which may be summarized as the mnemonic HAVOC score. We showed for the first time that COPD and PVD may represent strong predictors for longterm mortality in patients with low EF undergoing CABG. The predictive HAVOC score consists of only five factors and it is easy to calculate, even at bedside. 

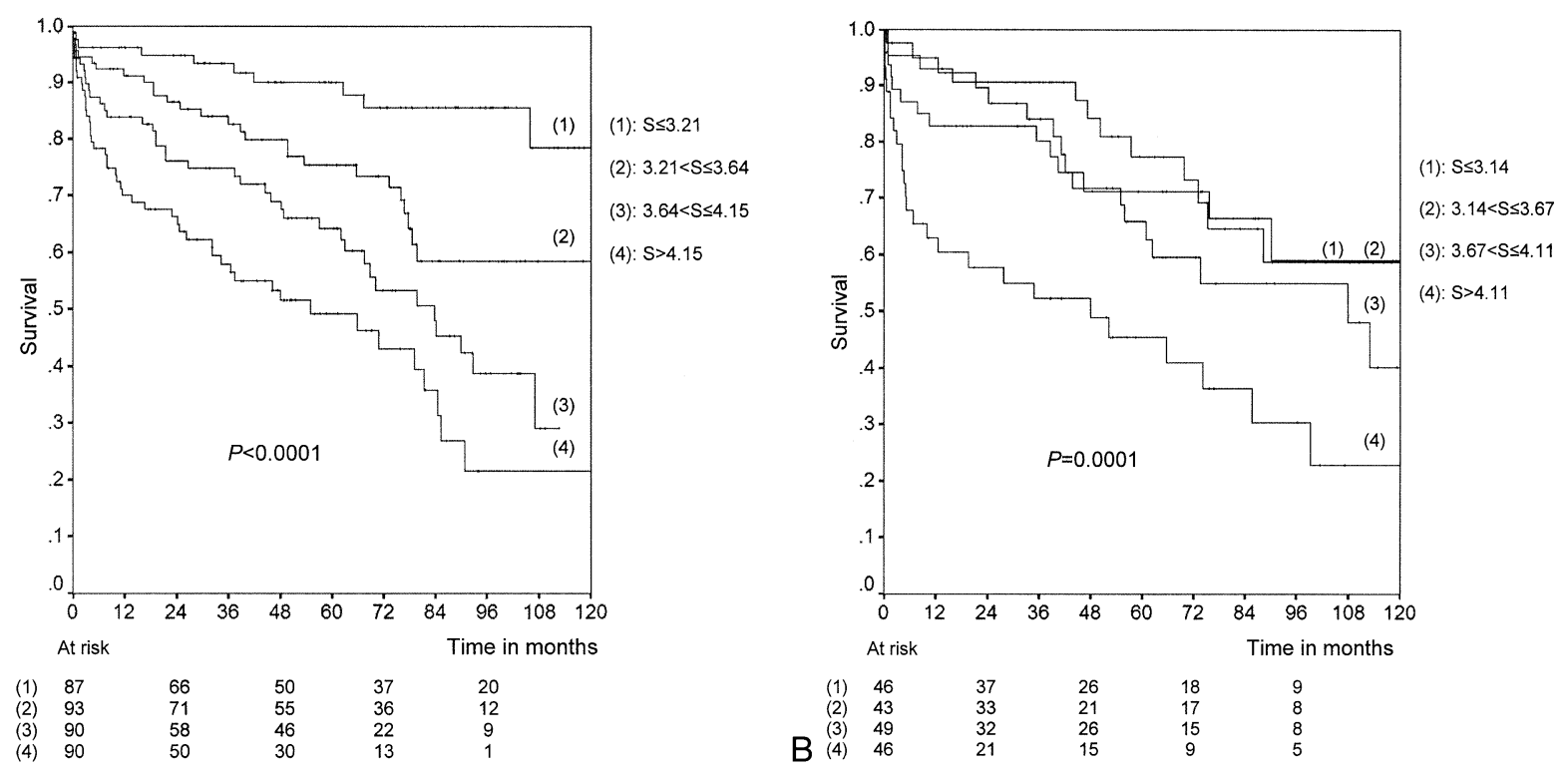

Figure 3. Kaplan-Meier curves of quartiles according to constructed score $S$ (split-sample approach) in training set of 360 patients $(A)$ and in validation set of 184 patients (B).

Several previous studies have examined preoperative risk factors in this population. Age is clearly a predictor of mortality risk. ${ }^{11,12,15}$ Several studies have also suggested that the severity of cardiac dysfunction, as measured by end-systolic volume index, ${ }^{15}$ number of previous myocardial infarctions, ${ }^{15}$ NYHA functional class IV status, ${ }^{8,11-13}$ and myocardial viability, ${ }^{6,16-18}$ are important determinants of death risk. The type of intervention is probably also important, and previously suggested determinants have included the quality of coronary arteries ${ }^{12,16}$ as well as emergency versus elective status, ${ }^{16}$ which was also identified as an independent predictor in our model. Female sex, diabetes, number of diseased vessels, and hypertension have been proposed in other studies ${ }^{14,19,26}$ but were not independently statistically significant in our data set, and they were also not found to be important in another large study. ${ }^{16}$

The identification of preoperative risk factors regarding the long-term mortality after CABG in patients with low EF is often hampered by limitations in the study designs, inadequate sample size or follow-up, and inconsistent definitions of low EF. Almost all the reports in the literature are retrospective investigations, and the prospective study by Shah and colleagues ${ }^{19}$ was limited to 57 patients. Moreover, these studies differed from our analysis in the preoperative factors being considered. Most of them did not analyze other extracardiac factors and comorbidities, such as COPD and PVD. Such factors were found in our analysis to be strong independent predictors for long-term mortality, and they suggest that pulmonary and vascular comorbidities may have a key impact in determining long-term outcome for these patients. Finally, there is no consensus in the literature regarding the definition of left ventricular dysfunction. We, along with others, ${ }^{8,26}$ analyzed patients with an $\mathrm{EF}$ of $25 \%$ or less, whereas still others have studied patients with an EF less than $30 \%{ }^{6,13,14,16}$ or even less than $40 \%{ }^{11,15,19}$ On the other hand, other groups have used more strict criteria and analyzed only patients with EF less than $20 \%{ }^{7,9,12}$ These differences in definitions may affect the importance of predictive factors.

Previous studies have noted a low rate of coronary revascularization in patients with ischemic cardiomyopathy. A retrospective study of reversible defects in patients with ischemic cardiomyopathy at Mayo Clinic revealed a revascularization rate of only $13 \%$ through 5 years. This low rate of revascularization reflects at least in part the absence of optimal treatment for this complex group of patients and points to the need for a randomized clinical trial. ${ }^{27}$ It also highlights that there is some skepticism regarding proceeding with $\mathrm{CABG}$ for these patients because of the uncertainty about their long-term outcomes. Severe low left ventricular dysfunction is known to increase morbidity and mortality after CABG. However, recent retrospective studies have shown that CABG in patients with an EF less than $30 \%$ can have an acceptable perioperative mortality, ranging from $4 \%$ to $11 \%$. $^{8-10,12,14,26}$ Patients demonstrate improvements in both left ventricular EF and NYHA functional class after surgical revascularization in most studies, ${ }^{8-11}$ and for some patients long-term survival may be feasible after CABG. The 5- and 10-year survivals in our study were $68 \% \pm 2 \%$ and $45 \% \pm 4 \%$, respectively, well in concordance with other recent studies in which 5-year survival rates have ranged from $56 \%$ to $72 \%{ }^{8,9,12,14,19,26}$ However, the patients 


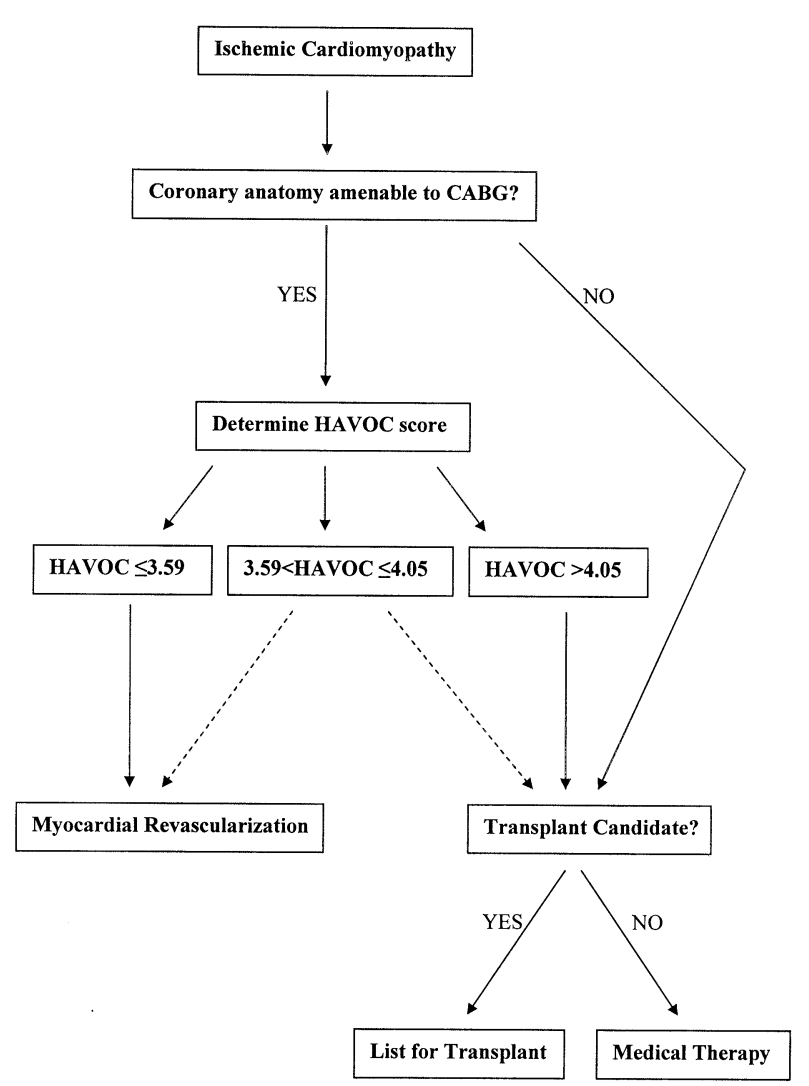

Figure 4. Algorithm for ischemic cardiomyopathy treatment according to developed HAVOC score. Patients with HAVOC scores between 3.60 and 4.05 (quartile above median of our data set) may be considered for either revascularization or transplantation candidacy.

undergoing $\mathrm{OPCAB}$ had a significantly lower long-term survival than those undergoing on-pump CABG. In our study this undoubtedly was related to selection bias, because the patients undergoing OPCAB had a significantly higher mean EuroSCORE. In addition, we have shown that the detrimental effect of OPCAB on midterm survival changed during the last 5 years in our institution after innovative techniques became available. ${ }^{28}$ The improvement in operative technique, the current application of robotic techniques, and the more common use of bilateral internal thoracic artery grafts may achieve even better survivals without any increase in operative mortality. $5,29,30$

Other than CABG, the other major option for therapy in ischemic cardiomyopathy is orthotopic heart transplantation. In determining whether a patient is a candidate for CABG or heart transplantation, a number of factors need to be considered. Heart transplantation is limited by a severe shortage of donor organs, considerable expense, moderate long-term survival, and need for continuous immunosuppression. However, it has been shown to be beneficial in patients with NYHA functional class IV symptoms refractory to medical management who have no other impairments. ${ }^{4}$ Unfortunately, transplantation remains an option limited to only a small number of patients. ${ }^{7}$ With the aging population, more patients are living well past the traditional age ceilings for acceptability onto a transplant list. The HAVOC score developed in this study may serve to guide physicians in making decisions regarding transplantation versus CABG. Thus the HAVOC score may be used to modify and clarify our previously proposed algorithm for selection of intervention in patients with ischemic cardiomyopathy (Figure 4). ${ }^{31}$

To test the robustness of our predictive modeling, we also performed a training-validation modeling exercise. This approach is stricter in assessing the adequacy of a predictive model because it evaluates its performance in a totally different data set from the one with which it has been developed. The model derived in the training set was similar to the one obtained when all data where considered, although understandably the two models were not exactly the same. Importantly, four of the five predictors were retained, and the magnitude of their effects was largely unchanged. Past CHF was not selected in the training-validation approach, perhaps because of more limited data. Even a model with four predictors, however, performed well on a completely different validation set and separated high- and low-risk quartiles with about 4-fold differences in the odds of death. In the absence of a good history on the extent of past CHF, the four-predictor score may also be used with quite satisfactory performance.

There are several limitations in this study. First, this was a retrospective investigation. Nevertheless, the information on preoperative risk factors was collected with highly standardized methods for the New York State database. Second, a most important limitation, is that preoperative myocardial viability, which has consistently been shown to be a strong predictor of long-term mortality, was not routinely determined. However, Samady and coauthors ${ }^{32}$ have shown that lack of improvement of ventricular function is associated with a similar survival and similar improvement of angina and heart failure as seen in patients with improved ventricular function, suggesting that in patients with low EF methods for assessment of myocardial viability may underestimate the potential for symptomatic and survival benefit achieved by CABG. Importantly, our model needs to be validated externally in data sets derived from other centers and settings. The split-sample approach ensures that the derived discriminatory ability is probably not inflated, but no internal validation approach (split-sample, bootstrapping, or other) can ensure satisfactory performance on different external data sets. For external applications, the coefficients of the HAVOC model may be shrunk (eg, by 0.78) to get more accurate estimates of expected survival. Nev- 
ertheless, we generally recommend that the HAVOC score should be used for general decision making on whether a patient exceeds the threshold for CABG candidacy, rather than for estimating the exact mortality risk. Finally, the cause of death in these patients is not documented and was not necessarily cardiac related, whereas survival in relation to graft patency is unknown. However, for practical purposes prediction of overall mortality is probably more important than prediction of cardiac deaths alone. Administrative follow-up can be extremely useful, particularly when the outcomes to be examined are limited to all-cause mortality, which is less prone to error than administrative coding of medical diagnoses or procedures. However, there are still limitations of this approach, including inability to match patients and to confirm a patient's status as alive.

In conclusion, and acknowledging these limitations, this first multivariable predictive score of midterm and longterm survival from a large patient database for many years should be helpful in determining the optimal therapy for the growing group of patients with ischemic cardiomyopathy.

\section{References}

1. Jessup M, Brozena S. Heart failure. N Engl J Med. 2003;348:2007-18.

2. Gheorghiade M, Bonow RO. Chronic heart failure in the United States: a manifestation of coronary artery disease. Circulation. 1998;97: 282-9.

3. O'Connor CM, Velazquez EJ, Gardner LH, Smith PK, Newman MF, Landolfo KP, et al. Comparison of coronary artery bypass grafting versus medical therapy on long-term outcome in patients with ischemic cardiomyopathy (a 25-year experience from the Duke Cardiovascular Disease Databank). Am J Cardiol. 2002;90:101-7.

4. Cope JT, Kaza AK, Reade CC, Shockey KS, Kern JA, Tribble CG, et al. A cost comparison of heart transplantation versus alternative operations for cardiomyopathy. Ann Thorac Surg. 2001;72:1298-305.

5. DeRose JJ, Ashton RC, Belsley S, Swistel DG, Vloka M, Ehlert F, et al. Robotically assisted left ventricular epicardial lead implantation for biventricular pacing. J Am Coll Cardiol. 2003;41:1414-9.

6. Hausmann H, Topp H, Siniawski H, Holz S, Hetzer R. Decisionmaking in end-stage coronary artery disease: revascularization or heart transplantation? Ann Thorac Surg. 1997;64:1296-301.

7. Tjan TD, Kondruweit M, Scheld HH, Roeder N, Borggrefe M, Schmidt C, et al. The bad ventricle-revascularization versus transplantation. Thorac Cardiovasc Surg. 2000;48:9-14.

8. Bouchart F, Tabley A, Litzler PY, Haas-Hubscher C, Bessou JP, Soyer $\mathrm{R}$. Myocardial revascularization in patients with severe ischemic left ventricular dysfunction. Long term follow-up in 141 patients. Eur J Cardiothorac Surg. 2001;20:1157-62.

9. Carr JA, Haithcock BE, Paone G, Bernabei AF, Silverman NA. Longterm outcome after coronary artery bypass grafting in patients with severe left ventricular dysfunction. Ann Thorac Surg. 2002;74:1531-6.

10. Elefteriades J, Edwards R. Coronary bypass in left heart failure. Semin Thorac Cardiovasc Surg. 2002;14:125-32.

11. Lorusso R, La Canna G, Ceconi C, Borghetti V, Totaro P, Parrinello $\mathrm{G}$, et al. Long-term results of coronary artery bypass grafting procedure in the presence of left ventricular dysfunction and hibernating myocardium. Eur J Cardiothorac Surg. 2001;20:937-48.

12. Mickleborough LL, Carson S, Tamariz M, Ivanov J. Results of revascularization in patients with severe left ventricular dysfunction. J Thorac Cardiovasc Surg. 2000;119:550-7.

13. Oliveira SF, Jatene AD, Solimene MC, de Oliveira SA, Meneguetti C, Jatene FB, et al. Coronary artery bypass graft surgery in patients with ischemic cardiomyopathy and severe left ventricular dysfunction: short and long-term results. Heart Surg Forum. 1999;2:47-53.

14. Trachiotis GD, Weintraub WS, Johnston TS, Jones EL, Guyton RA, Craver JM. Coronary artery bypass grafting in patients with advanced left ventricular dysfunction. Ann Thorac Surg. 1998;66:1632-9.

15. Hamer AW, Takayama M, Abraham KA, Roche AH, Kerr AR, Williams BF, et al. End-systolic volume and long-term survival after coronary artery bypass graft surgery in patients with impaired left ventricular function. Circulation. 1994;90:2899-904.

16. Kleikamp G, Maleszka A, Reiss N, Stuttgen B, Korfer R. Determinants of mid- and long-term results in patients after surgical revascularization for ischemic cardiomyopathy. Ann Thorac Surg. 2003;75: 1406-12.

17. Pagley PR, Beller GA, Watson DD, Gimple LW, Ragosta M. Improved outcome after coronary bypass surgery in patients with ischemic cardiomyopathy and residual myocardial viability. Circulation. 1997;96:793-800.

18. Sawada S, Bapat A, Vaz D, Weksler J, Fineberg N, Greene A, et al. Incremental value of myocardial viability for prediction of long-term prognosis in surgically revascularized patients with left ventricular dysfunction. J Am Coll Cardiol. 2003;42:2099-105.

19. Shah PJ, Hare DL, Raman JS, Gordon I, Chan RK, Horowitz JD, et al. Survival after myocardial revascularization for ischemic cardiomyopathy: a prospective ten-year follow-up study. J Thorac Cardiovasc Surg. 2003;126:1320-7.

20. Nashef SA, Roques F, Hammill BG, Peterson ED, Michel P, Grover FL, et al. Validation of European System for Cardiac Operative Risk Evaluation (EuroSCORE) in North American cardiac surgery. Eur J Cardiothorac Surg. 2002;22:101-5.

21. Williams BC, Demitrack LB, Fries BE. The accuracy of the National Death Index when personal identifiers other than Social Security number are used. Am J Public Health. 1992;82:1145-7.

22. Cox DR. Regression models and life-tables. J R Stat Soc. 1972;34: 187-220.

23. Steyerberg EW, Harrell FE Jr, Borsboom GJ, Eijkemans MJ, Vergouwe Y, Habbema JD. Internal validation of predictive models: efficiency of some procedures for logistic regression analysis. J Clin Epidemiol. 2001;54:774-81.

24. Kaplan EL, Meier P. Nonparametric estimation from incomplete observations. J Am Stat Assoc. 1958;53:547-81.

25. Ioannidis JP, Lau J. Heterogeneity of the baseline risk within patient populations of clinical trials: a proposed evaluation algorithm. Am J Epidemiol. 1998;148:1117-26.

26. Milano CA, White WD, Smith LR, Jones RH, Lowe JE, Smith PK, et al. Coronary artery bypass in patients with severely depressed ventricular function. Ann Thorac Surg. 1993;56:487-93.

27. Miller WL, Tointon SK, Hodge DO, Nelson SM, Rodeheffer RJ, Gibbons RJ. Long-term outcome and the use of revascularization in patients with heart failure, suspected ischemic heart disease, and large reversible myocardial perfusion defects. Am Heart J. 2002;143:904-9.

28. Toumpoulis IK, Anagnostopoulos CE, Katritsis DG, Shennib H, DeRose JJ, Swistel DG. Influence of innovative techniques on midterm results in patients with minimally invasive direct coronary artery bypass and off-pump coronary artery bypass. Heart Surg Forum. 2004;7:31-6

29. Ioannidis JP, Galanos O, Katritsis D, Connery CP, Drossos GE, Swistel DG, et al. Early mortality and morbidity of bilateral versus single internal thoracic artery revascularization: propensity and risk modeling. J Am Coll Cardiol. 2001;37:521-8.

30. Lytle BW, Blackstone EH, Loop FD, Houghtaling PL, Arnold JH, Akhrass R, et al. Two internal thoracic artery grafts are better than one. J Thorac Cardiovasc Surg. 1999;117:855-72.

31. DeRose JJ Jr, Oz MC. Surgical alternatives to transplantation and assist devices in the treatment of heart failure. Curr Cardiol Rep. 2000;2:564-71.

32. Samady H, Elefteriades JA, Abbott BG, Mattera JA, McPherson CA, Wackers FJ. Failure to improve left ventricular function after coronary revascularization for ischemic cardiomyopathy is not associated with worse outcome. Circulation. 1999;100:1298-304. 